Article

\title{
Classifying the Baltic Sea Shallow Water Habitats Using Image-Based and Spectral Library Methods
}

\author{
Ele Vahtmäe * and Tiit Kutser \\ Estonian Marine Institute, University of Tartu, Mäealuse 14, 12618 Tallinn, Estonia; \\ E-Mail: tiit.kutser@sea.ee \\ * Author to whom correspondence should be addressed; E-Mail: Ele.vahtmae@sea.ee; \\ Tel.: +372-671-8946; Fax: +372-671-8900.
}

Received: 15 March 2013; in revised form: 30 April 2013 / Accepted: 2 May 2013 /

Published: 16 May 2013

\begin{abstract}
The structure of benthic macrophyte habitats is known to indicate the quality of coastal water. Thus, a large-scale analysis of the spatial patterns of coastal marine habitats enables us to adequately estimate the status of valuable coastal marine habitats, provide better evidence for environmental changes and describe processes that are behind the changes. Knowing the spatial distribution of benthic habitats is also important from the coastal management point of view.
\end{abstract}

A big challenge in remote sensing mapping of benthic habitats is to define appropriate mapping classes that are also meaningful from the ecological point of view. In this study, the benthic habitat classification scheme was defined for the study areas in the relatively turbid north-eastern Baltic Sea coastal environment. Two different classification methods-image-based and the spectral library-method were used for image classification. The image-based classification method can provide benthic habitat maps from coastal areas, but requires extensive field studies. An alternative approach in image classification is to use measured and/or modelled spectral libraries. This method does not require fieldwork at the time of image collection if preliminary information about the potential benthic habitats and their spectral properties, as well as variability in optical water properties exists from earlier studies. A spectral library was generated through radiative transfer model HydroLight computations using measured reflectance spectra from representative benthic substrates and water quality measurements.

Our previous results have shown that benthic habitat mapping should be done at high spatial resolution, owing to the small-scale heterogeneity of such habitats in the Estonian 
coastal waters. In this study, the capability of high spatial resolution hyperspectral airborne a Compact Airborne Spectrographic Imager (CASI) sensor and a high spatial resolution multispectral WorldView-2 satellite sensor were tested for mapping benthic habitats. Initial evaluations of habitat maps indicate that image-based classification provides higher quality benthic maps compared to the spectral library method.

Keywords: Baltic Sea; benthic habitat mapping; CASI; WorldView-2; image processing; spectral library; HydroLight

\section{Introduction}

The Baltic Sea is currently considered as one of the most polluted sea areas in the world [1]. In order to avoid further deterioration of ecological conditions of the Baltic Sea, the surrounding countries should aim at an over-reaching cross-border marine spatial planning. Spatial planning decisions (borders of protected areas, locations of infrastructure, etc.) require data over large areas, but currently, the decisions are made based on insufficient data, as the costs of in situ measurements (diving, video, grab sampling) are too high. Thus, the lack of scientifically sound background information and/or the high cost of getting the information are limiting the effectiveness of spatial planning in coastal waters.

The structure of benthic macrophyte habitats are also known to indicate the quality of coastal waters. For example, the abundance of perennial macroalgae Fucus vesiculosus, which is considered as one of the indicator species in the Baltic Sea, has been reducing gradually [2,3]. Eutrophication enhances the growth of opportunistic filamentous algae, which are known to out-compete slow-growing perennial macrophytes, such as Fucus vesiculosus [4]. Due to the direct relationships between submerged aquatic vegetation and water quality, trends in the changes of vegetation cover indicate the state of water in the coastal areas [5]. Thus, a large-scale analysis of the spatial patterns of coastal marine habitats enables us to adequately estimate the status of coastal marine habitats, provide better evidence for environmental changes and describe processes that are behind the changes.

Mapping of substrate cover types and their biophysical properties based on their reflectance properties have been carried out successfully in optically clear waters [6]. However, the full potential of remote sensing is still to be exploited, particularly in temperate, sublittoral environments, where under certain situations, the poor water clarity has been a limiting factor [7]. The Baltic Sea is an intracontinental shallow marine environment under the strong influence of human activities and terrestrial material. Large discharge from rivers, limited exchange with marine waters of the North Sea and a relatively shallow sea floor significantly influence the optical properties of the Baltic Sea [8]. The Baltic Sea represents an optically complex water body with high concentration of colored dissolved organic matter [9] and suspended particles [9,10], as well as frequent phytoplankton blooms [11]. High concentrations of optically active substances in the water column often prevent mapping of benthic substrates in the Baltic Sea [12].

Remote sensing data have proved to be extremely useful in providing maps of marine benthic habitats [13-18]. Different authors have used image-based classification method, which can provide 
benthic habitat maps from the coastal areas, but require extensive field studies [19-26]. Image-based supervised classification techniques (Maximum Likelihood, Spectral Angle Mapper etc.) are based on the identification of training classes in the remote sensing image by selecting Regions of Interest (ROIs) over spatially and spectrally homogeneous targets. Spectral signatures for each training class are built by calculating image statistics. Finally, all image pixels are assigned to the training class to which its spectral signature is the most similar.

The disadvantage of supervised classification technique is that it requires the collection of training data, which is relatively time-consuming and expensive. Furthermore, the results are not easily comparable between images, because the number and types of classes in images acquired with the same instrument at the same location may vary depending on illumination and/or atmospheric conditions [14]. Therefore, the problem that faces the supervised classification of multi-temporal images is that the training data has to be repeatedly selected for each image within the multi-temporal remote sensing data [27]. In addition, the performance of the supervised classification technique depends on the selection of training areas. The quality of training data can significantly influence the performance of an algorithm and, thus, the classification accuracy. Inappropriate placement or too few training pixels in a training site produces statistics unrepresentative of the land or benthic cover classes of interest [28]. The more experience and knowledge the map producer has from the study area, the more accurate that maps can be produced. The experience of the person processing the image can help to decide whether it's necessary to add or remove training areas in order to receive more reasonable results. Selecting a good set of training areas is often tedious, labor-intensive and takes long time [29].

An alternative approach in image classification is to use measured and/or modeled spectral library [14,30,31]. In the spectral library approach, remote sensing reflectances (Rrs) of individual image pixels are compared to simulated Rrs spectra created using measured values of bottom reflectance and water inherent optical properties. The advantage of spectral library classification approach is that it does not require extensive field surveys [14], but the optical properties of benthic substrates and optical properties of the water column have to be known. At the same time, classifying the image with the modeled spectral library requires high quality atmospheric correction. If a modeled spectral library is used in image classification, then the library spectra are correct from the physics point of view. If atmospheric correction is not applied or the result of atmospheric correction is not accurate, then there is a significant difference between remotely sensed spectral radiance and the measured or modeled spectral library. These differences may negatively influence the accuracy of classification. Another option would be creating a top of atmosphere spectral library. For example, Kutser et al. [14] showed that applying a top of atmosphere spectral library on atmospherically uncorrected images produces better classification results than applying a just above water spectral library on atmospherically corrected images. This approach, however, requires a forward atmospheric model that allows one to propagate just above the water surface spectra through the atmosphere.

On the other hand, classification methods like the Spectral Angle Mapper (SAM) are relatively insensitive to illumination and albedo effects, since it is invariant to absolute values of reflectance. Reflectance spectra are normalized in SAM before comparison to each other. SAM can be applied on the part of the spectrum where the characteristic features of a particular target occur, and it is possible to change the "accuracy" SAM is using while comparing target spectra with the spectra from the spectral library. 
It would be instructive to evaluate and compare the ability of different image classification approaches, as both of them have their advantages and disadvantages. In the present paper, we also tested the suitability of two different sensors for benthic habitat mapping: a high spatial resolution airborne hyperspectral CASI and a spaceborne multispectral WorldView-2. The image-based classification approach and spectral library classification approach were applied to both of the image data. The quality of benthic habitat maps derived using both classification approaches were determined by the quantitative process of accuracy assessment using field measurements from the study area.

\section{Material and Methods}

\subsection{Study Area}

The study was carried out in the Haapsalu Bay, which is situated in the West Estonian Archipelago Sea area, the north-eastern Baltic Sea (Figure 1). Haapsalu Bay, with its total area of about $50 \mathrm{~km}^{2}$, extends deeply into the land in the western part of Estonia [32]. The bay is relatively shallow, with the maximum depth less than $5 \mathrm{~m}$ and an average depth of 1.5-2 $\mathrm{m}$. The inner part of the bay is very shallow, with a maximum depth approximately one meter [32]. The eastern and central parts of the bay are separated by peninsulas, causing limited water exchange $[33,34]$.

The visibility in the Haapsalu bay is often low, due to the high concentration of colored dissolved organic matter; therefore, the water often appears brownish. Overall, the area is one of the less transparent coastal areas in Estonia and, therefore, the maximum depths, where benthic habitats can be detected from the surface, are quite low $(2-3 \mathrm{~m})$.

The bed sediments consist of sands, gravels and clays of various structures [33]. Isolation, low exposure, shallowness, substrate availability and moderate-to-strong inflow of nutrients explain the development of rich phytobenthic communities in Haapsalu Bay [33]. The most important benthic vegetation species in the study area are higher order plants, Potamogeton pectinatus and Myriophyllum spicatum. Both species occur in high numbers in the entire bay, often reaching the surface. In addition, rich Charophyte sp. communities are growing on shallower sandy areas.

Figure 1. Location of the Haapsalu Bay in the West Estonian Archipelago Sea, the Baltic Sea (left), Haapsalu Bay imaged by WorldView-2 satellite with $2 \mathrm{~m}$ spatial resolution on 2 July 2011 (right).
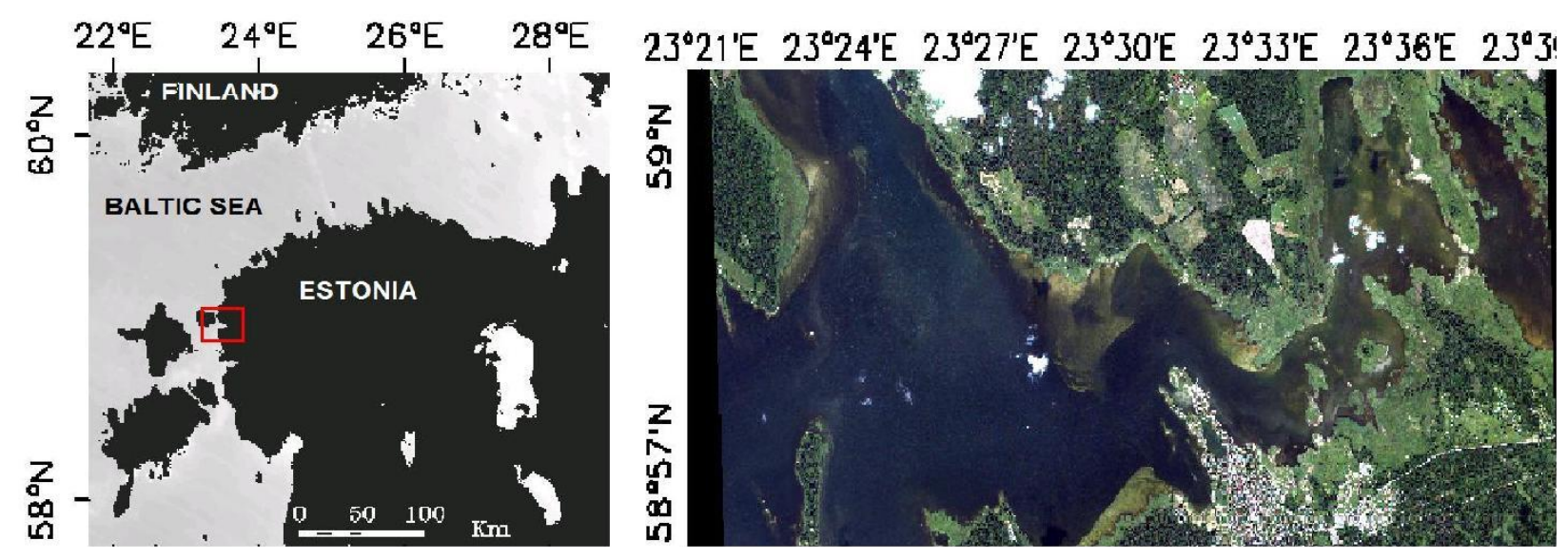


\subsection{Field Survey}

Field observations in the Haapslau Bay were acquired concurrently with a remote sensing campaign from 4 to 8 July 2011, to provide ground reference data for image interpretation. In order to describe benthic habitats, underwater video records and water depth measurements together with their Global Positioning System (GPS) coordinates were taken from more than 100 field sites. The total coverage of macrophytes, coverage of visually distinguishable species and substrate were estimated from the video data using the continuous video estimation method described by Möller et al. [35]. The collected field data was used for classifying and validating the remote sensing data.

Reflectance measurements were carried out in the study area using the RAMSES hyperspectral radiometers, built by TriOS GmbH (Germany), in order to assess the quality of atmospheric correction and HydroLight model simulations. Measurements were conducted in the visible and near-infrared range of the spectrum (350-900 nm). Downwelling light was measured by the irradiance sensor and upwelling light by the radiance sensor above the water surface. In order to determine the above water reflectance, the upwelling radiance $(\mathrm{Lu})$ was divided by the downwelling irradiance (Ed). Atmospheric correction was performed by Fast Line-of-sight Atmospheric Analysis of Spectral Hypercubes (FLAASH) and resulted in an irradiance reflectance image. Therefore, RAMSES remote sensing reflectance was converted to the irradiance reflectance by multiplying by the Q-factor. The Q-factor is defined as the ratio of upwelling irradiance to upwelling radiance $(\mathrm{Q}=\mathrm{Eu} / \mathrm{Lu})$. For this study, the Q-factor was taken equal to $\pi(\mathrm{Q}=\pi)$, as in case of an isotropic upwelling radiance distribution. In reality, the Q-value generally ranges from 3 to 6 steradians [36].

The reflectance measurements were carried out above different homogeneous shallow water bottom types present in the study area. In total, 70 different measurement stations were visited on which multiple reflectance measurements were performed and for which the average spectrum was calculated. The spectra collected by the RAMSES spectrometer were resampled to match with CASI and WorldView-2 spectral bands by using the spectral response functions of the bands of both sensors.

In addition, the spectral library classification approach requires knowledge to be established about the optical properties of different benthic habitats and about the optical properties of the waters in the study area. Therefore, spectral measurements were obtained with the RAMSES spectrometer for all representative marine vegetation species and communities without water column influence. Samples of different vegetation species and bare sediment types (sand, pebble, etc.) were taken out of the water, and reflectance measurements were made by placing the sample on a black plastic bag in order to avoid a background signal. Pure species spectra were measured for all the main vegetation species occurring in the study area. In addition, as vegetation did not always grow as dense patches, reflectance for the community was performed as a mixture of measurements from vegetation and sediment. In four different locations, water samples were taken for chlorophyll, suspended matter and colored dissolved organic matter (CDOM) measurements to characterize the optical properties of the water column.

\subsection{Spectral Library}

A radiative transfer numerical model, HydroLight 5.0 [37], was used to predict the reflectance of different bottom types above the water surface depending on their depth and optical water properties. 
This model uses optical properties of the water column, sea surface state, bottom albedo and sky conditions to obtain the radiance distribution within and leaving a water body [38]. Input data for HydroLight was collected during the field campaign and included water constituents, such as chlorophyll, colored dissolved organic matter and suspended matter, benthic reflectance without overlaying the water column and local environmental conditions, such as the day, time, wind speed and cloud cover.

During field campaigns, water samples from different locations were collected. Measurements of water samples at different sites showed spatial variations. For example, chlorophyll-a concentration varied between 2.41 and $6.39 \mathrm{mg} / \mathrm{m}^{3}$, suspended matter (tripton) concentration between 0.8 and $6.0 \mathrm{mg} / \mathrm{L}$ and absorption by Colored Dissolved Organic Matter (CDOM) at $380 \mathrm{~nm}$ varied between 2.03 and $5.76^{-1}$. Two different sets of water constituents were used in the HydroLight model (Table 1). Water type 1 represents clear open waters and water type 2 brownish CDOM rich waters.

The spectral library modeled by HydroLight was calculated for the bottom reflectance spectra of sand, Charophytes and higher order vegetation at different densities. The benthos was assumed to be a Lambertian reflector in the modeling. Each bottom reflectance was modeled at depths from 0.1 to $3 \mathrm{~m}$ in $0.5 \mathrm{~m}$ intervals. The output provides an estimate of the remotely sensed signal, including both the effects of bottom brightness and water column contribution. An optically deep spectrum was also included, describing the reflectance expected from the water column alone with no influence from the benthos. The modelling was carried out for two different water types with the concentration of optically active substances shown in the Table 1.

Table 1. Concentrations of optically active substances used in HydroLight model simulations. $\mathrm{C}_{\mathrm{Chl}}$ and $\mathrm{C}_{\mathrm{SM}}$ are concentrations of chlorophyll-a and total suspended matter, respectively, and $\mathrm{a}_{\mathrm{CDOM}}(380)$ is absorption by Colored Dissolved Organic Matter (CDOM) at wavelength $380 \mathrm{~nm}$.

\begin{tabular}{cccc}
\hline Water Type & $\mathbf{C}_{\mathbf{C h l}}$ & $\mathbf{C}_{\mathbf{S M}}$ & $\mathbf{a}_{\text {CDOM }}(\mathbf{3 8 0})$ \\
\hline 1 & 2.65 & 4.40 & 2.03 \\
2 & 6.39 & 3.20 & 4.61 \\
\hline
\end{tabular}

\subsection{Remote Sensing Data}

\subsubsection{CASI}

Airborne hyperspectral data was collected on 6 July 2011 using the CASI (Compact Airborne Spectrographic Imager, Itres, Calgary, AB, Canada) sensor owned by the Institute for Environmental Solutions, Latvia. A spectral range of the instrument is $370-1,054 \mathrm{~nm}$, and widths of the spectral bands are programmable. A total of 25 spectral bands were used at wavelengths where different benthic types have distinct spectral features (Table 2). The number and width of the bands were also optimized taking into account low water, leaving the signal and the speed of the aircraft. Most of the spectral bands were around $5 \mathrm{~nm}$, except the first and last bands, which were around $20 \mathrm{~nm}$ wide. The aircraft was flown at altitude of $2,000 \mathrm{~m}$, resulting in a pixel resolution of $1 \mathrm{~m}$.

Radiometric correction and geo-correction of the data was performed by the Latvian Institute for Environmental Solutions, i.e., the institute carrying out the CASI flights. ENVI ${ }^{\circledR}$ (Research Systems 
Inc.) was used to further process the imagery prior to the spectral analysis and mapping. The flight lines were mosaicked together. Sun-glint was removed using the deglinting model of Hedley et al. [39]. The deglinting process was applied to the sensor radiance values, prior to estimating reflectance and correcting for atmospheric effects.

Table 2. Band-set configuration of Compact Airborne Spectrographic Image (CASI)-configured for this study.

\begin{tabular}{cccc}
\hline Band & Wavelength $(\mathbf{n m})$ & Band & Wavelength $(\mathbf{n m})$ \\
\hline 1 & $367.6-372.4$ & 14 & $646.9-651.7$ \\
2 & $396.2-401.0$ & 15 & $670.7-675.5$ \\
3 & $436.8-441.6$ & 16 & $697.0-701.8$ \\
4 & $455.9-460.7$ & 17 & $716.1-720.9$ \\
5 & $477.4-482.2$ & 18 & $737.5-742.3$ \\
6 & $496.5-501.3$ & 19 & $756.6-761.4$ \\
7 & $517.9-522.7$ & 20 & $775.7-782.9$ \\
8 & $546.6-551.4$ & 21 & $816.3-821.1$ \\
9 & $565.7-570.5$ & 22 & $835.4-840.2$ \\
10 & $587.2-592.0$ & 23 & $875.4-882.6$ \\
11 & $599.1-603.9$ & 24 & $935.5-942.7$ \\
12 & $618.2-623.0$ & 25 & $1,035.7-1,054.7$ \\
13 & $625.4-632.6$ & & \\
\hline
\end{tabular}

Atmospheric correction was performed using the FLAASH module in ENVI, which converts the radiance image to reflectance data. FLAASH (Fast Line-of-sight Atmospheric Analysis of Spectral Hypercubes) is a MODTRAN-4-based atmospheric correction software package developed by the Spectral Sciences, Inc., and the Air Force Phillips Laboratory [40]. We specified visibility values for FLAASH using an iterative empirical approach comparing retrieved reflectances with in situ surface reflectance made at the study area. The visibility value yielded the closest comparison when in situ spectra was $60 \mathrm{~km}$. FLAASH was run using the atmospheric model of mid-latitude summer and a maritime aerosol profile.

Availability of in situ reflectance data, although collected not exactly at the time of satellite overpass, allowed us to correct the FLAASH product further. Linear relationships were developed between the FLAASH atmospherically corrected reflectance values and in situ RAMSES above water surface reflectance values for each spectral band in order to improve the atmospheric correction.

\subsubsection{WorldView-2}

The WorldView-2 (WV2) multispectral image was collected on July 2, 2011. WV2 generates images with a spatial resolution of $2 \mathrm{~m}$ in multispectral mode. WV2 increases the number of spectral bands from the traditional 4 in the visible and near-infrared spectrum (blue $450-510 \mathrm{~nm}$, green 510-580 nm, red 630-690 nm, NIR1 770-895 nm) to 8 bands (new bands: coastal 400-450 nm, yellow 585-625 nm, red edge 705-745 nm, NIR2 860-1040 nm) [41].

The image used in this study was geometrically corrected by the image supplier (DigitalGlobe). The image was radiometrically corrected, i.e., the raw digital numbers were converted to the top-of-atmosphere radiance. The absolute radiometric calibration factor was obtained from the metadata supplied together 
with the WV2 imagery. This step was performed using the WV2 Radiance Calibration Utility in ENVI's pre-processing software package. Atmospheric correction was performed using the FLAASH module similarly as it was done in the case of CASI data. The visibility value yielded the closest comparison when in situ spectra was $40 \mathrm{~km}$.

\subsubsection{Classification}

The collected underwater videos were analyzed for sediment properties and macrophyte species composition and coverage. The aim of the benthic habitat classification was to separate the bottom types in the study area into the sets of spectral classes that represent the patterns and texture of the ecosystem. Five broad classes (Figure 2) were defined based on our experience and knowledge from the study area and labelled as "hard bottom with ephemeral algae," "dense higher-order plant habitats" (vegetation $>50 \%$ ), "dense charophyte community" (vegetation $>50 \%$ ), "sparse higher order plants and/or Charophytes on soft bright bottom" (vegetation $<50 \%$ ) and "optically deep water ( $>2 \mathrm{~m})$." Brown algae and red algae were excluded from the classification scheme, as those algae were identified only in one-two field stations and at low quantity (less than $30 \%$ coverage).

Figure 2. Classes defined for benthic habitat classification in the water and on the dry land prepared for the reflectance measurement: (a) hard bottom with ephemeral algae, (b) dense higher-order plant habitats, (c) dense Charophyte community, (d) sparse higher order plants and/or Charophytes on soft bright bottom.

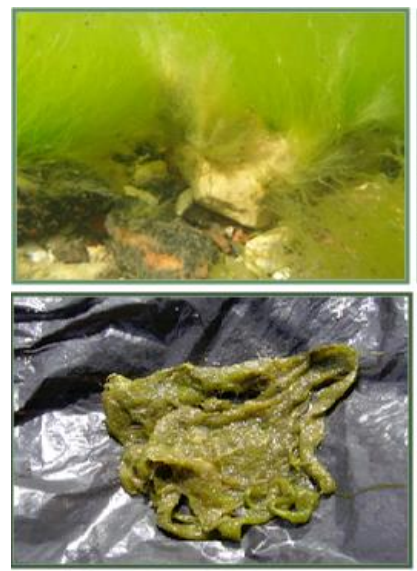

(a)

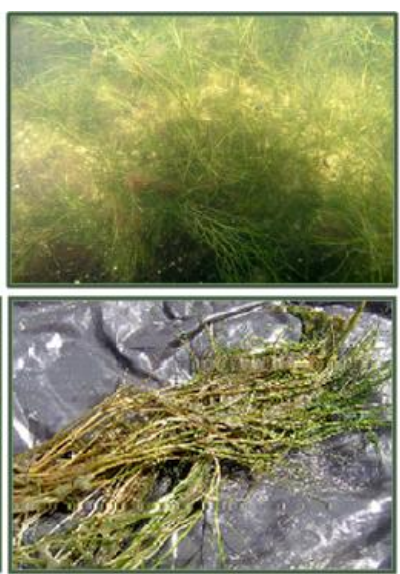

(b)

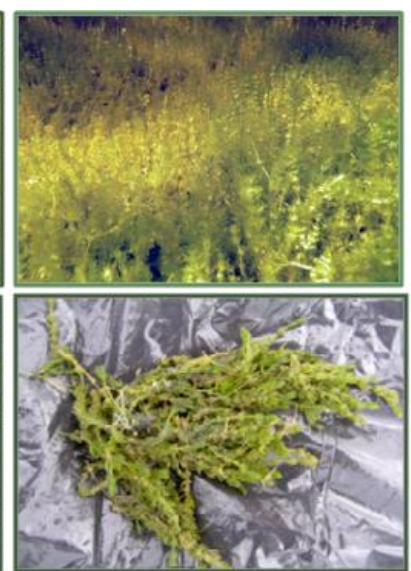

(c)

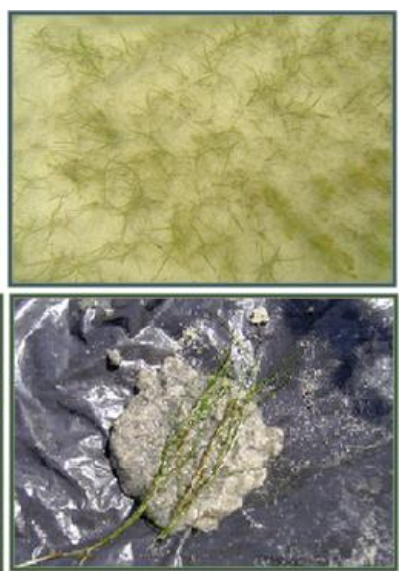

(d)

First of all, the supervised classification procedure was applied to both of the remote sensing images. Field data from ground-truth stations, as well as spectrally similar areas close to the field control points and expert knowledge on the area, were used for image classification. Initially, different supervised classification algorithms were tested, such as the Spectral Angel Mapper (SAM), Minimum Distance, Maximum Likelihood, etc. These classifiers were selected, because they are most widely used by different authors. Initial accuracy assessment indicated that the SAM classification algorithm provided best results in the case of both sensors, and therefore, it was used in the following analysis.

The second approach used for classifying the images was based on the modelled spectral library (see Section 2.3) and the Spectral Angle Mapper algorithm. SAM compares the angle between the reference spectrum (library) and each image pixel in the $n$-dimensional space [42]. Smaller angles 
represent closer matches to the reference spectrum. This technique, when used on calibrated reflectance data, is relatively insensitive to illumination and albedo effects, primarily responding to spectral shape similarities and differences [42].

The quality of benthic habitat maps derived from the airborne CASI and spaceborne WorldView-2 data was determined by the quantitative process of accuracy assessment. Field data from ground-truth stations were used for the accuracy assessment of the classification. These data were not included in the training of the supervised classification. Overall, accuracy and the Kappa coefficient $(\kappa)$ were used as statistical measures of the agreement between the output map of classification and ground-truthed data. $\kappa$ is expressed as:

$$
\kappa=\frac{N \sum_{i=1}^{r} x_{i i}-\sum_{i=1}^{r}\left(x_{i+} \times x_{+i}\right)}{N^{2}-\sum_{i=1}^{r}\left(x_{i+} \times x_{+i}\right)}
$$

where $\mathbf{N}$ is the total number of observations included in the matrix, $\mathbf{r}$ is the number of rows in the confusion matrix, $\mathbf{x}_{\mathbf{i i}}$ is the number of observations in row $\mathbf{i}$ and column $\mathbf{i}$ (on the major diagonal), $\mathbf{x}_{\mathbf{i}+}$ is the total observations in row $\mathbf{i}$ and $\mathbf{x}_{+1}$ is the total of observations in column $\mathbf{i}$.

\section{Results}

\subsection{Image-Based Classification}

First, the image-based classification method was applied to both of the remote sensing images, whereas the classification scheme was the same in both occasions. Five different benthic habitat classes were defined for the imaged area based on the video data and expert knowledge: "hard bottom with ephemeral algae," "dense higher-order plant habitats," "dense charophyte community," "sparse higher order plants and/or Charophytes on soft bright bottom" and "optically deep water (>2 m)." As indicated previously [12,43], the spectral appearance of the same habitat type varies depending on the water depth and water quality. Therefore, training regions were selected from different water depths and water quality conditions for each benthic habitat class. Altogether, 21 initial supervised classes were generated for the CASI image and 24 initial classes for the WorldView-2 image. Initial classes were later merged into the five habitat classes of interest. Classification results achieved by the SAM algorithm for both remote sensing sensors are presented in Figure 3.

The classification results estimate that the Haapsalu Bay area was mostly covered by Charophytes community, which grows on shallower sandy areas. Dense higher-order plant habitats (e.g., Potamogeton sp., Myriophyllum sp.) were found on soft bright bottom deeper down both in the inner and outer part of the bay. At depths of more than $2 \mathrm{~m}$, the signal from benthic vegetation was already considered insignificant, due to high concentrations of optically active substances in the water. This impeded mapping of benthic substrates in deeper waters. The hard bottom with ephemeral algae occurred at shallow depths near the coast in outer part of the bay and also as patches in the inner part of the bay.

The performance of classification was evaluated in terms of the Confusion Matrix. The thematic accuracy of classification results were determined by comparing classified habitats with that of the observed habitat type. Training and validation ROIs were non-overlapping and allowed a statistical 
assessment of the classifier performance. Ninety-five field control points were used for the accuracy assessment in case of WorldView-2 data. The field control points distributed between benthic habitat classes are, accordingly: hard bottom with ephemeral algae (5 field points), dense higher-order plant habitats (24 field points), dense Charophyte community (32 field points), sparse higher order plants and/or Charophytes on soft bright bottom ( 8 field points) and optically deep water (26 field points).

Figure 3. Benthic habitat maps of the Haapsalu Bay area produced from (a) CASI airborne imagery and (b) Worldview-2 space borne imagery using image-based classification approach, SAM classification algorithm and five benthic classes described in Figure 2.

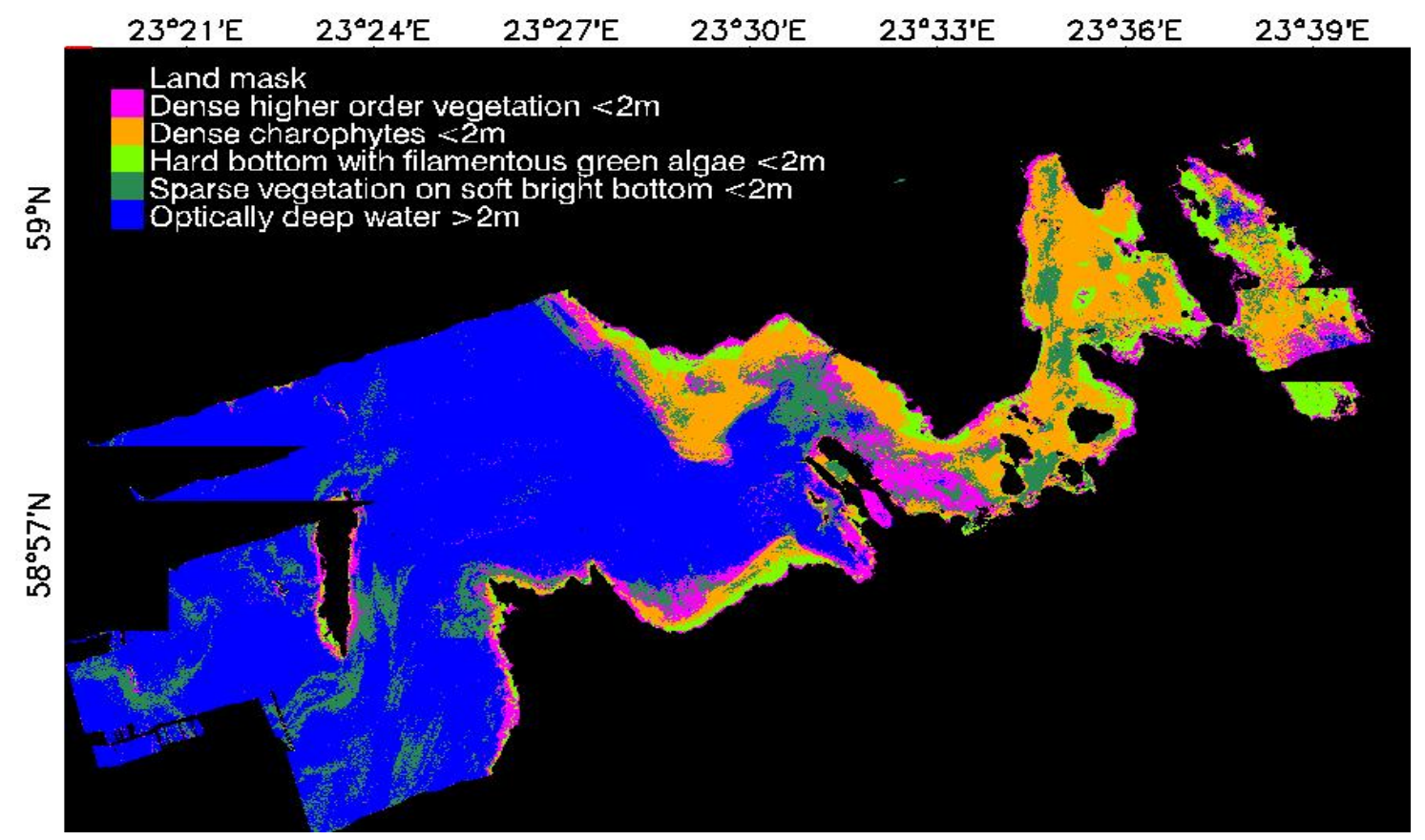

(a)

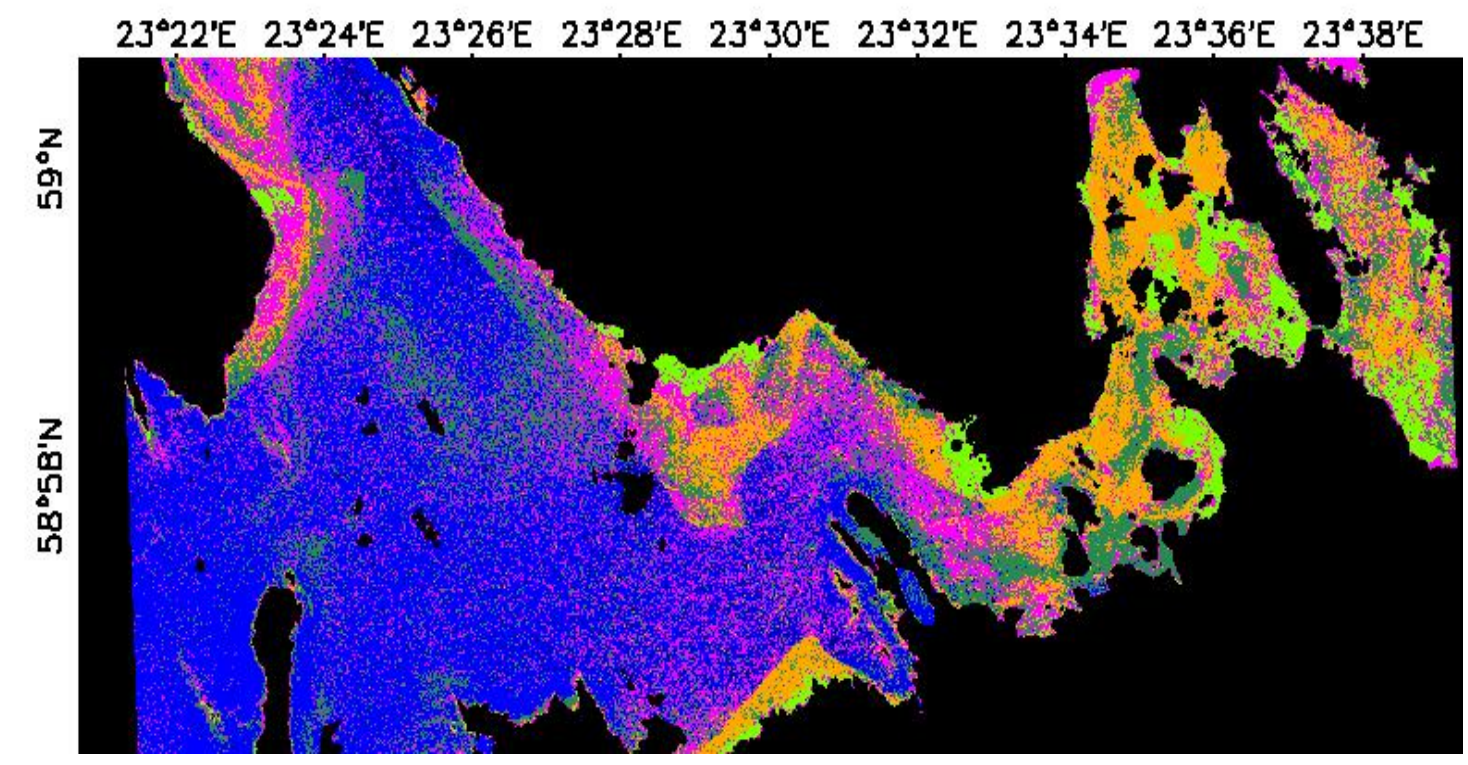

(b)

Eighty-nine field control points were used in the case of CASI data, as some of the field stations were situated outside of the CASI imaged area. The field control points distributed between benthic 
habitat classes are, accordingly: hard bottom with ephemeral algae (5 field points), dense higher-order plant habitats (23 field points), dense Charophyte community (32 field points), sparse higher order plants and/or Charophytes on soft bright bottom ( 7 field points) and optically deep water (22 field points).

The overall accuracy assessment was $77.5 \%$ for the CASI image and $71.6 \%$ in the case of the WorldView-2 image. The kappa coefficient $(\kappa)$ is also commonly used for accuracy assessment, as it removes random agreement from the overall accuracy. A $\kappa$ value between 0.40 and 0.80 represents moderate agreement between the classified remote sensing image and reference data [44]. The $\kappa$ values were 0.70 in the case of CASI data and 0.62 in the case of WorldView-2 data (Table 3).

Hyperspectral CASI data gave slightly better results compared to the multispectral WorldView-2 data. Producer and user accuracy are ways of reporting individual class accuracies. User accuracy reflects the likelihood that a habitat class on the map actually exists on the ground. Since the main aim of the current study is to produce maps for people to use, the user accuracy is the more important of the two. In the case of CASI data, low user accuracy was identified for the class "sparse higher order plants and/or Charophytes on soft bright bottom" (38\%). In the case of WorldView-2 data, low user accuracies were identified for classes "hard bottom with ephemeral algae" (33\%) and "sparse higher order plants and/or Charophytes on soft bright bottom" (50\%).

Table 3. Classification accuracy (overall accuracy, kappa coefficient) of the hyperspectral CASI and multispectral WorldView-2 images using image-based classification approach and spectral library classification approach (FLAASH: images are atmospherically corrected using FLAASH; FLAASH calibrated: images are first atmospherically corrected with FLAASH and then calibrated by RAMESE in situ reflectance values).

\begin{tabular}{ccc}
\hline & Overall Accuracy & Kappa Coefficient \\
\hline CASI image-based classification & $77.5 \%$ & 0.70 \\
CASI spectral library classification (FLAASH) & $57.5 \%$ & 0.43 \\
CASI spectral library classification (FLAASH calibrated) & $70.8 \%$ & 0.61 \\
WV-2 image-based classification & $71.6 \%$ & 0.62 \\
WV-2 spectral library classification (FLAASH) & $64.6 \%$ & 0.52 \\
WV-2 spectral library classification (FLAASH calibrated) & $63.5 \%$ & 0.53 \\
\hline
\end{tabular}

3.2. Spectral Library Classification

\subsubsection{Atmospheric Correction}

Classifying the image with the modeled spectral library requires high quality atmospheric correction. In the case of satellite data, the atmospheric contribution is more than $90 \%$ from the measured signal over the dark object, such as deep water. The effect of the atmosphere must be removed in order for image spectra to match library spectra. The results of the FLAASH atmospheric correction were examined by comparing extracted image reflectance spectra with the field measurements performed with RAMSES spectroradiometers.

Figures 4 and 5 show some examples of atmospherically corrected image spectra, corresponding RAMESE spectra and HydroLight modeled spectra. It must be noted that the HydroLight model produced consistently lower reflectance values than RAMESE, as well as atmospherically corrected 
CASI and WorldView-2 data. It can be explained with the parameterization of HydroLight. We used several empirical equations embedded in HydroLight. These have been mainly developed on data from clear oceanic water and are most probably not valid in the Baltic Sea. For example, we used just one backscattering coefficient for suspended matter and phytoplankton, while our previous results [45] show that total backscattering coefficient may vary by more than two-orders of magnitude in the Baltic Sea. This has significant impact on the absolute value of reflectance, but a little impact on the shape, as the backscattering coefficient spectra are usually flat, except in the case of cyanobacteria [46].

FLAASH corrected CASI spectra showed negative values in the blue spectral region (400-450 nm); therefore, these spectral bands were removed from the following analysis. Vegetation itself absorbs light strongly at shorter wavelengths [47]. Therefore, the only part of the spectrum useful for shallow water benthic habitat mapping even in clear oceanic waters is green to the NIR part of spectrum. In the Baltic Sea, the light at shorter wavelengths is strongly absorbed by CDOM. As a result, reflectance values are low, below $500 \mathrm{~nm}$. On the other hand, absorption of light by water molecules increases exponentially with increasing wavelength from $650 \mathrm{~nm}$ onwards. Therefore, the features useful for mapping shallow water benthic habitats are lost quickly with increasing water depths (see Figure 4).

Figure 4. Comparisons of RAMSES ground-truth spectra with CASI FLAASH atmospheric correction results (primary axis) and HydroLight modelling results (secondary axis). FLAASH: images are atmospherically corrected with FLAASH; FLAASH calibrated: atmospherically corrected images calibrated by RAMSES in situ reflectance values; HydroLight 1: water type 1 was used in model simulations; HydroLight 2: water type 2 was used in model simulations (see Table 1).
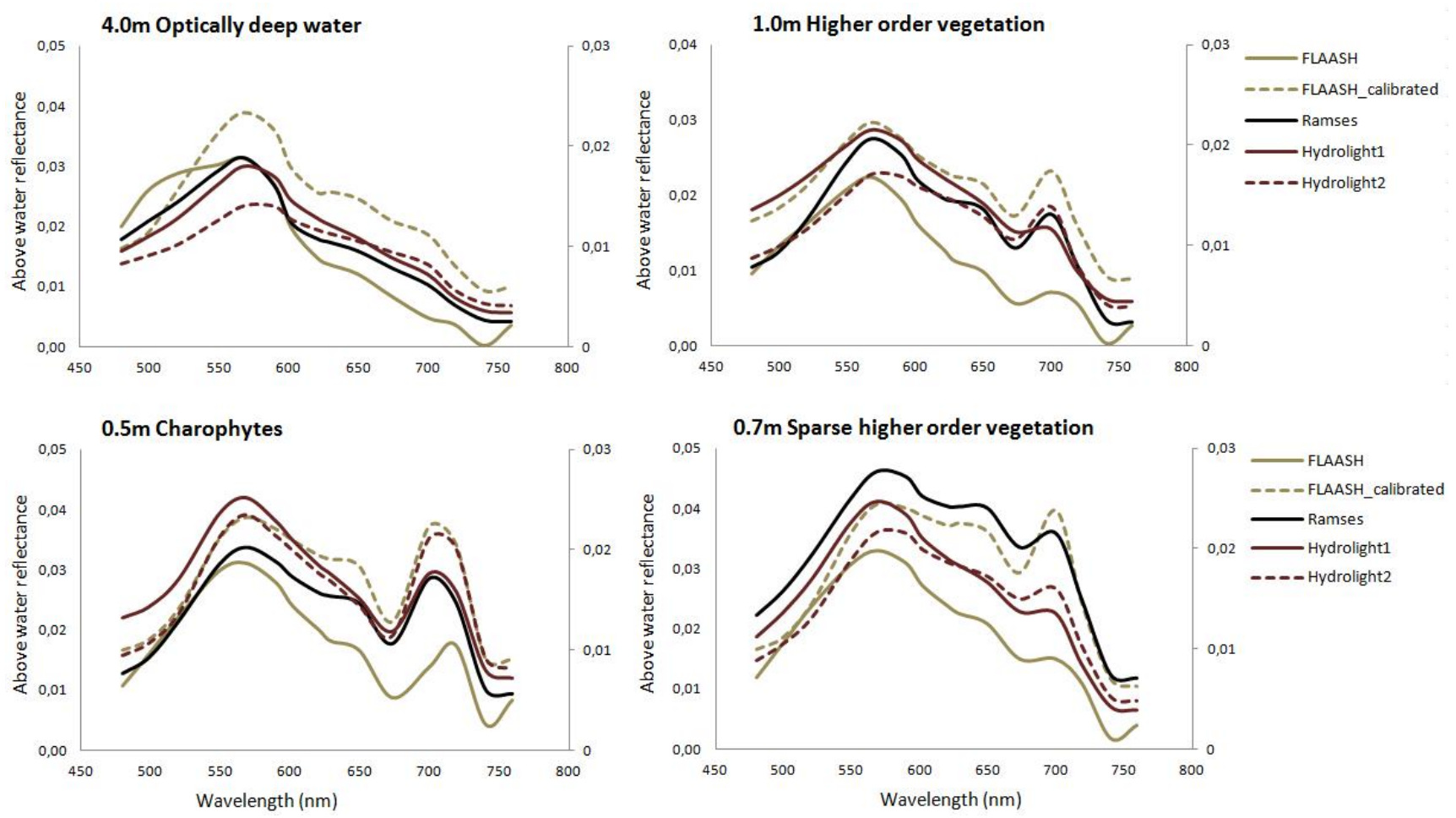

Figure 4 indicates that the FLAASH correction worked relatively well in removing atmospheric effects. Especially take into account that we used SAM in further image processing, as SAM is normalizing both spectral library and image spectra before comparing them. The biggest discrepancies 
between the field and airborne FLAASH corrected data occurred near $700 \mathrm{~nm}$, as can be seen in the Figure 4. This is partly caused by the optical effect caused by selected CASI bands. The configuration of bands we used had band 16 near $700 \mathrm{~nm}$ (697-701.8) and band 17 (716.1-720.9) further away. The actual peak in reflectance spectra was often between those two bands. Plotting CASI spectra as continuous values (when there are actually discrete bands) creates an illusion that the peak is shifted towards red (compared to the RAMSES continuous spectra). However, there may also be slight calibration issues with the band 16, as calibrating CASI spectra with in situ measured field data allowed us to get a reflectance peak that resembles more field data.

It must be noted that the spatial heterogeneity of benthic habitats is very high in Estonian coastal waters. It means that the reflectance from a $1 \mathrm{~m}^{2}$ area may consist of signals from tens of different benthic algae and some substrate signal. The RAMSES measurement area is just a few square centimeters. Therefore, the CASI and RAMSES reflectances do not have to match, even if they were measured in exactly the same location.

Figure 5. Comparisons of RAMSES ground-truth spectra with WorldView-2 FLAASH atmospheric correction results (primary axis) and HydroLight modelling results (secondary axis). FLAASH: images are atmospherically corrected with FLAASH; FLAASH calibrated: atmospherically corrected images calibrated by RAMSES in situ reflectance values; HydroLight 1: water type 1 was used in model simulations; HydroLight 2: water type 2 was used in model simulations (see Table 1).
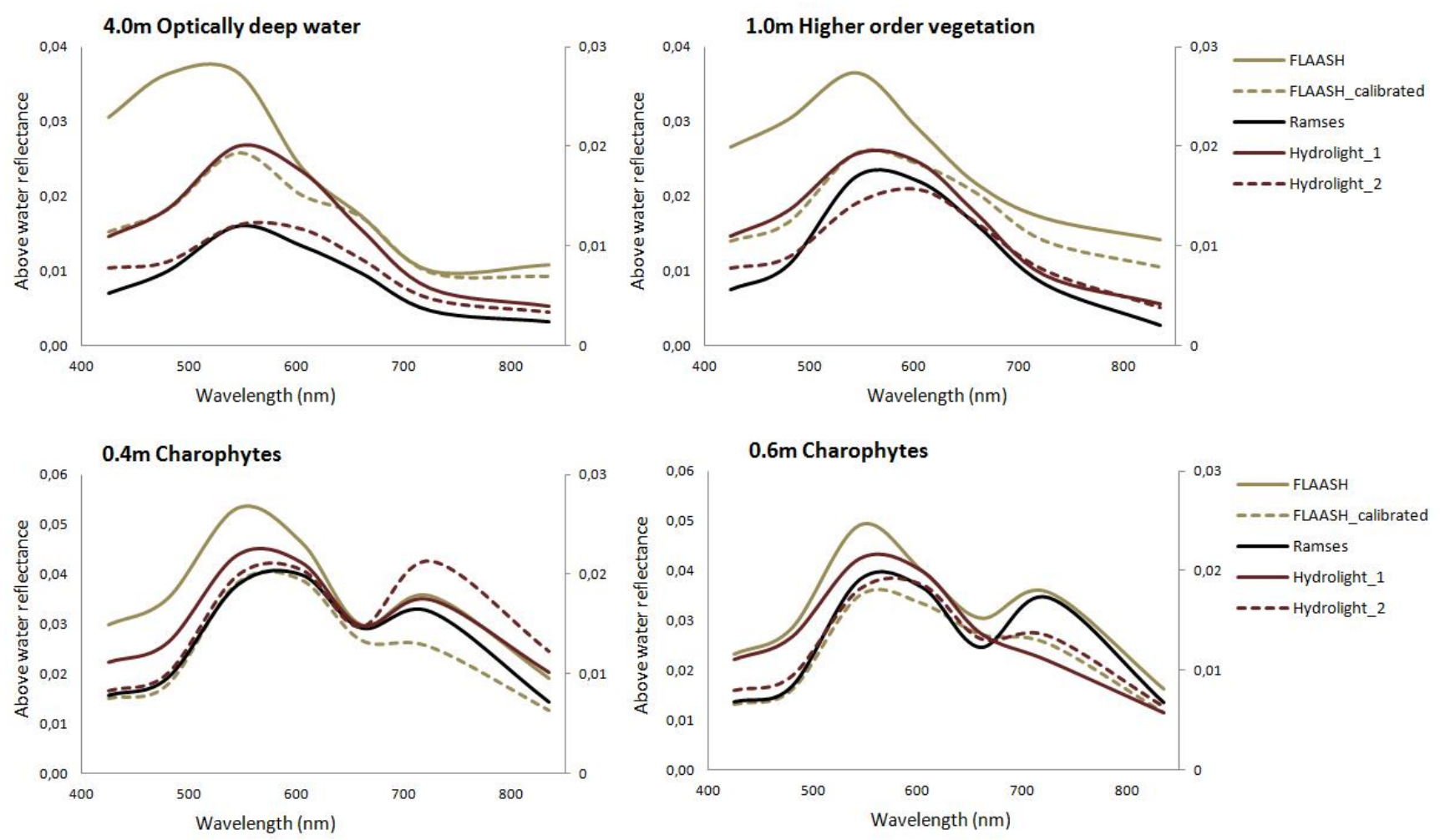

Atmospheric correction of WorldView-2 data with FLAASH produced reasonable results. In some cases, the reflectance values in the blue bands were high compared to the RAMSES spectra (see top graphs in Figure 5). A possible explanation of this effect may be a glint inWorldView-2 imagery in these pixels, as our results [48] show that the glint contribution in reflectance spectra is the highest in 
the UV and blue part of the spectrum and decreases with increasing wavelength. In many cases, the FLAASH corrected reflectances match nicely with the field data. In some cases, the FLAASH corrected reflectances match better with the spectra modeled with HydroLight than the field data. As mentioned above, the satellite spectra from the $4 \mathrm{~m}^{2}$ area cannot match with the RAMSES spectra measured from a few square centimeters in the case of very heterogeneous bottoms, like in most of the study area.

\subsubsection{Classification}

First, the modeled spectral library was applied to the atmospherically corrected images (FLAASH). Then, linear regression relationships were developed between the FLAASH atmospherically corrected reflectance values and in situ RAMSES above water surface reflectance values in order to improve the atmospheric correction (FLAASH calibrated). The modeled spectral library was applied also to FLAASH calibrated images. Each pixel in the image was assigned to a benthic habitat and water depth class corresponding to the spectrum in the library that most closely matched the CASI and WorldView-2 spectrum of this particular pixel. The spectral library consisted of spectra that were modeled for two different water types (Table 1). SAM classification was performed thrice for all the remote sensing images - first, only spectra that were modeled with water type 1 were used; secondly, only spectra with water type 2 were used; and thirdly, water type 1 and water type 2 spectra were used together.

Figure 6. Benthic habitat maps of the Haapsalu Bay area produced from (a) CASI FLAASH calibrated imagery and (b) Worldview-2 FLAASH corrected imagery using spectral library classification approach, SAM classification algorithm and five benthic classes, described in Figure 2.

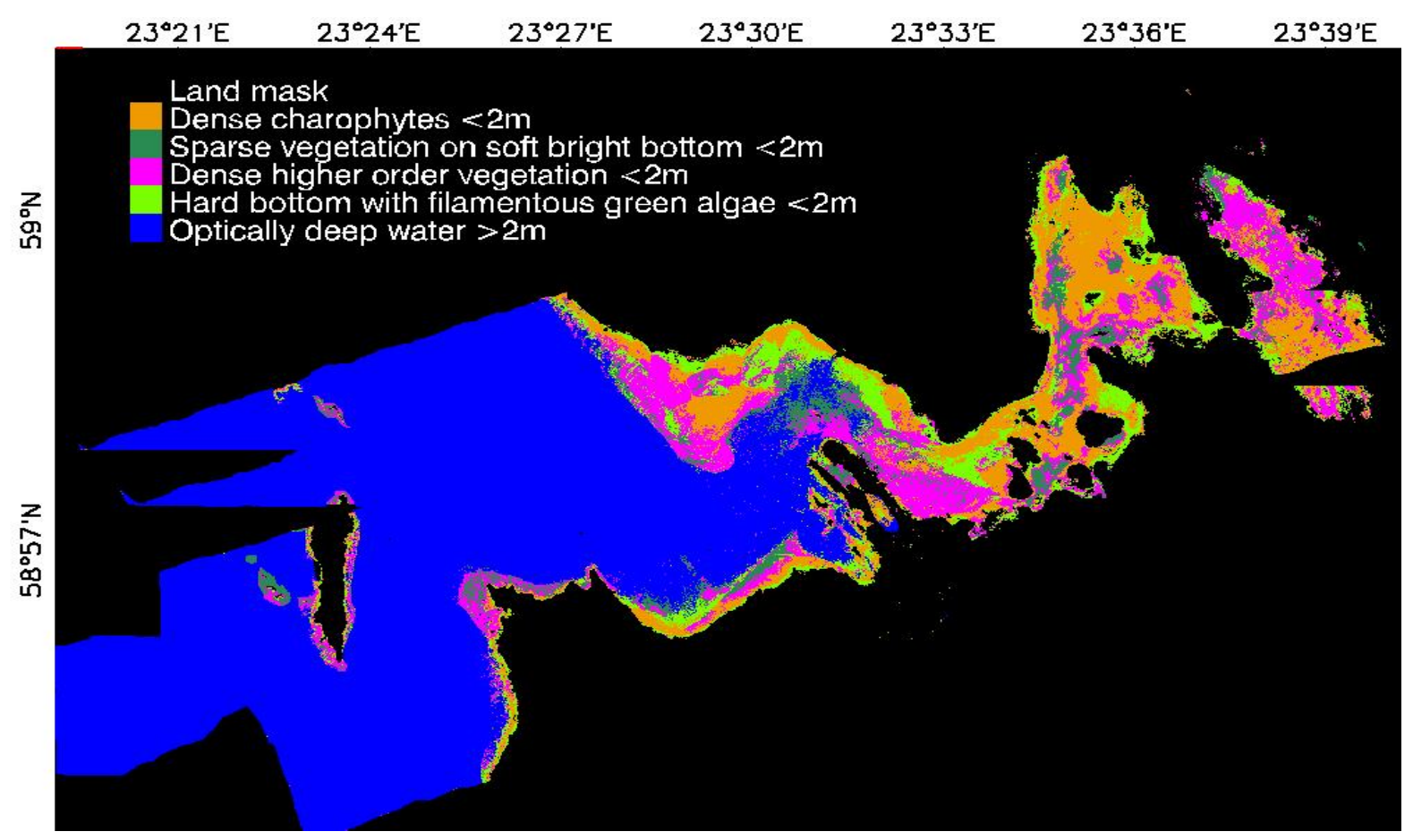

(a) 
Figure 6. Cont.

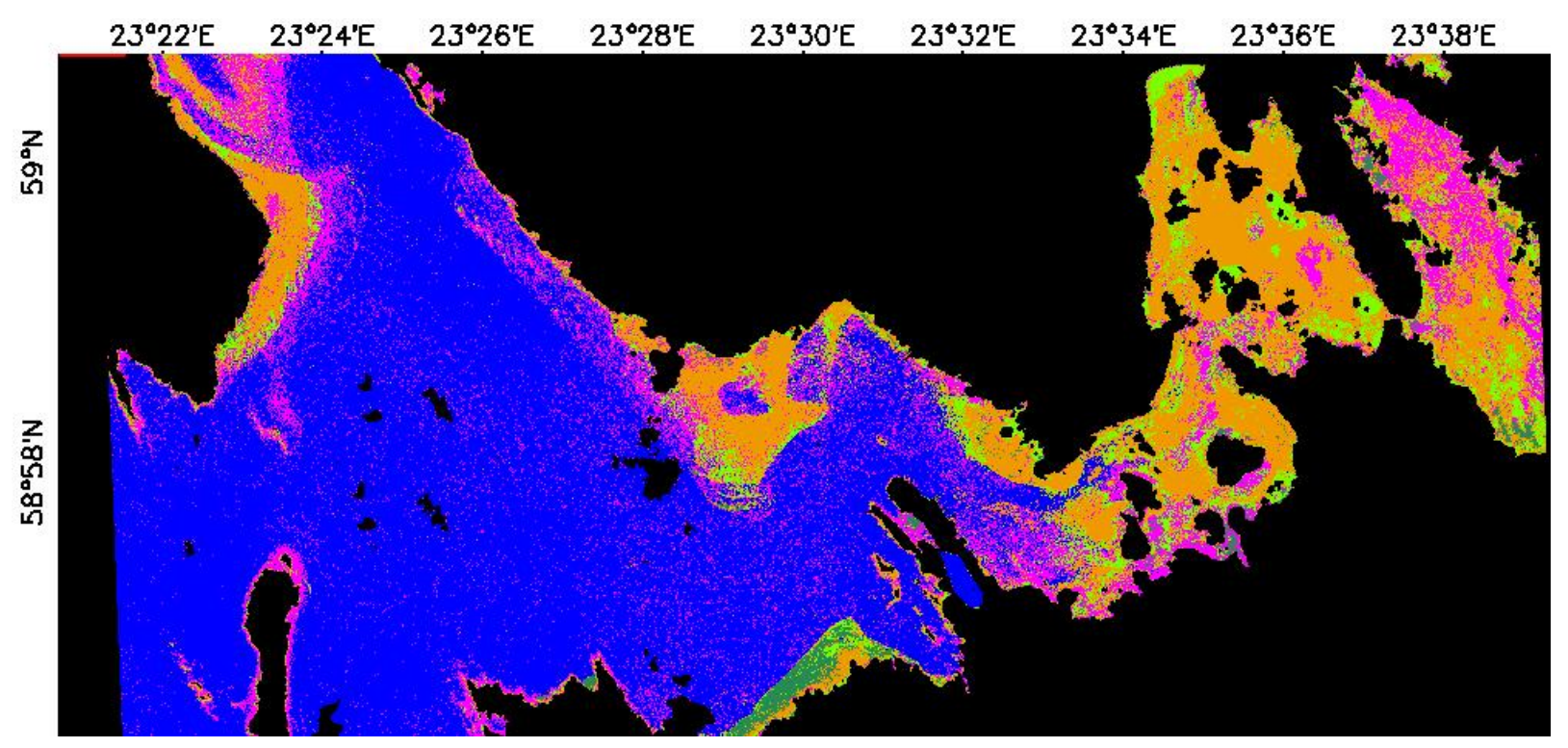

(b)

The spectral library classification approach gave poorer results compared to the image-based classification approach. However, applying the spectral library to the FLAASH calibrated CASI image substantially improved the classification results (Table 3). The best results were achieved when using water type 1 and water type 2 modeled spectra together and using wavelengths between 520 and $739 \mathrm{~nm}$. The overall accuracy was $70.8 \%$ and a $\kappa$ value 0.61 . The classification results are shown in Figure 6, where all the benthic classes at different depths are merged into one single habitat class. It must be noted that deep water areas were masked out from CASI data before applying the classification. The reason was that on that day, some deep water areas had a phytoplankton bloom, causing a peak near $700 \mathrm{~nm}$. This effect caused a situation where the deep water pixels containing high phytoplankton biomass were classified as some type of benthic habitat.

In the case of multispectral WorldView-2 data, applying the spectral library to the FLAASH calibrated image did not improve the classification result. The best result was achieved when using only water type 1 modeled spectra. In this case, the overall accuracy was $64.6 \%$ and a $\kappa$ value 0.52 .

\section{Discussion}

Optical remote sensing systems are limited by depth penetration and constrained by water turbidity. In clearest ocean waters, optical remote sensing is limited to depths below $30 \mathrm{~m}$. This is mainly due to the high transparency of water in the blue end of the spectrum. On the other hand, most of the spectral information useful for separating different bottom types is actually in the red part of the spectrum, where the limiting factor for the remote sensing is absorption of light by water molecules. The useful information in this part of the spectrum can be obtained down to 5-6 $\mathrm{m}$, both in clear oceanic and relatively turbid coastal waters. The effects of high concentrations of suspended solids, dissolved organic substances and phytoplankton on remotely sensed signals make interpretation of substratum types increasingly difficult, as the water depth penetration is drastically reduced.

The depth limit for remote sensing was quite low in the Haapsalu Bay area compared to our previous results from benthic habitat mapping in Estonian coastal waters. For example, the benthic 
vegetation signal rapidly decreases as water depth increases and almost completely disappears within a depth of $2.0 \mathrm{~m}$ in the Haapsalu Bay area. The results from more open sea areas on the western side of the Estonian biggest island of Saaremaa showed that the benthic vegetation could be detected down to depths of 5-6 m [43]. Therefore, the areas below $2.0 \mathrm{~m}$ were classified as deep-turbid in the Haapsalu Bay area, where no information about benthic types could be retrieved with remote sensing.

While providing benthic habitat maps by using the image-based classification procedure, it should be kept in mind that the results may vary depending on the selection of the training regions. The more experience and knowledge the map producer has from the study area, the more accurate maps can be produced, as the map producer can decide whether it's necessary to add or remove training areas. For example, several supervised classification procedures were conducted in the study area using similar benthic habitat classes, but a different selection of training regions. A different selection of training regions means that initial training regions for each habitat class were selected only from multiple depths $(0.5 \mathrm{~m}, 1.0 \mathrm{~m}, 1.5 \mathrm{~m})$, but the results of the classification showed that there was confusion between certain classes. The amount of training regions was gradually increased by taking into account the water quality differences in the inner and outer part of the Haapslau Bay. Visual assessment of mapping results indicated that slightly different selection of training regions produced different representations of benthic community composition. The final selection of training regions was based on the expert knowledge of the study area.

Hyperspectral CASI data gave slightly better results compared to the multispectral WorldView-2 data, while using the image-based classification approach. Similar results have been shown by many different authors. For example, Belluco et al. [49] concluded that classifications of hyperspectral salt marsh data are somewhat superior to those from multispectral observations. Hochberg et al. [50] showed that the hyperspectral sensors provide the best areal benthic cover estimates, followed first by the narrow-band then the broad-band multispectral sensors. Phinn et al. [15] also concluded that the airborne hyperspectral CASI data produced a higher overall mapping accuracy than the multispectral QuickBird data for seagrass mapping. Multispectral data typically do not contain enough spectral information to differentiate between complex bottom types. In contrast, hyperspectral data, characterized by a high number of spectral bands, are capable of capturing this diversity [30]. Therefore, hyperspectral instruments, such as CASI, AISA and HyMap, have been recently favored by many authors $[16,17,51]$, as the spectral features, which are used to differentiate among benthic substrates, are narrow.

The accuracy assessment (Table 3) showed relatively high accuracy (77.5\%) in the case of classifying CASI hyperspectral image by the image-based classification approach. The main confusion was to distinguish the class "sparse higher order plants and/or Charophytes on soft bright bottom" from classes "dense charophyte community" and "dense higher-order plant habitats." In all cases, the substrate is relatively bright, and the reflectance of green algae and higher order plants is also relatively similar [52]. The reflectance signal depends on the density of the vegetation and in cases where the vegetation cover is $40-45 \%$, the substrate can sometimes give the signal of dense vegetation patches.

Deeper areas $(>2 \mathrm{~m})$ were also well differentiated from the shallower areas while using the image-based classification approach. A high proportion of field reference points from areas below $2 \mathrm{~m}$ significantly increased the overall accuracy. Therefore, the Kappa coefficient was calculated. The 
Kappa coefficient represents the proportion of agreement obtained after removing the proportion of agreement that could be expected to occur by chance [53]. It is widely used, because all elements in the classification error matrix, and not just the main diagonal, contribute to the Kappa calculation [54]. The value of the Kappa coefficient was 0.7 in the case of the CASI data, which indicates a moderate agreement between the classified remote sensing image and reference data.

The accuracy assessment (Table 3 ) showed lower accuracy (71.6\%) in the case of the WorldView-2 image-based classification approach. The main problem was to accurately map classes "hard bottom with ephemeral algae" and "sparse higher order plants and/or Charophytes on soft bright bottom". Similarly to CASI data, the class "sparse higher order plants and/or charophytes on soft bright bottom" was confused with classes "dense charophyte community" and "dense higher-order plant habitats." Unfortunately, we only had a few field reference stations for the class "hard bottom with ephemeral algae", and only one of them was classified correctly. The value of the Kappa coefficient was 0.62 in the case of WorldView-2 data, which indicates a moderate agreement between the classified remote sensing image and reference data.

Modelled spectral libraries were used as an alternative approach in image classification. The benthic reflectance spectra and water quality data were collected in the study site. The HydroLight 5.0 radiative transfer model allowed us to simulate water reflectance spectra for all possible combinations of bottom types, water depth and its optical properties. Nevertheless, classifying the image with the modelled spectral library requires the high quality of the image data, i.e., the reflectance spectra in the atmospherically corrected image have to be of high quality.

Different authors have used various atmospheric modelling programs, such as 6S radiative transfer code [49,51,55], ATCOR-Atmospheric Correction model [49] and ACORN [56], in order to retrieve surface reflectance from remote sensing images. In the current case, the FLAASH atmospheric correction procedure was selected, as it is a plug-in available in the ENVI image processing software and because it has shown to provide realistic water reflectance spectra over coral reefs in clear oceanic waters, dark boreal lakes, as well as intense cyanobacterial blooms [14,57-60].

The biggest discrepancies between the field data and FLAASH-corrected CASI data occurred near $700 \mathrm{~nm}$. Calibrating CASI atmospherically corrected spectra with the RAMSES measurements allowed us to get a reflectance peak that resembles the field data more. This method produced useable water spectra with characteristic features present in the reflectance spectra of different shallow water habitats $[61,62]$. At the same time, the calibration of WorldView-2 FLAASH corrected spectra with the RAMSES measurements did not provide considerable improvement.

The performance of atmospheric correction was assessed by comparing the spectra of atmospherically corrected image pixels with the RAMSES spectrometer spectra collected exactly in the same places. It must be noted that the area seen by different sensors is quite different. For example, the field of view of RAMSES radiance sensor measuring upwelling light is $7^{\circ}$, resulting in a sampling area of just centimeters in diameter. The CASI pixel size is $1 \mathrm{~m}^{2}$, but we selected $3 \times 3$ image pixels around the RAMSES sampling points; their average was compared with the RAMSES reflectance. This means that the CASI spectra cannot match exactly with the RAMSES spectra if the bottom was not homogenous.

The spectral library classification method provided poorer classification results compared to the image-based classification approach. The accuracy assessment for WorldView-2 data showed a 64.6\% 
overall accuracy. The spectral library modelled by using only water type 1 gave superior results than using spectral library modelled by both water types (Table 1). Here, we can assume that multispectral data do not contain enough spectral information to differentiate all the subtle changes conditioned by slightly different water quality. As a result, a large number of end-members may be confusing for the classification software, because many of the spectra may be almost identical.

The spectral library classification results in the case of CASI data showed relatively good results while applying the spectral library to the CASI FLAASH corrected image, which was calibrated with the RAMSES in situ reflectance values. The best results were achieved while using water type 1 and water type 2 modeled spectra together and using wavelengths between 520 and $739 \mathrm{~nm}$.

In the current study, a spectral library of remote sensing reflectance was simulated just above the water surface using a water column radiative transfer model. The spectral library was then used for classifying atmospherically corrected images by end-member matching. This has also been found to introduce noise that can confuse classifiers and interpreters alike [14]. The second option would be the creation of spectral libraries of radiances at the sensor altitude using "forward" modelling and then using the simulated libraries for classifying the at sensor (original data) radiance images against the modelled end-member libraries. The advantage here is that original image signal to noise ratio (SNR) is not modified by the processing [14]. However, we do not have an atmospheric forward model to test this approach.

The glint correction procedure was also necessary in the case of CASI data, as the image suffered from severe sun glint effect. The implementation of glint correction procedure to the pixels not actually contaminated with glint reduced the reflectance values of those pixels, resulting in a bigger difference between the in situ measured spectra and atmospherically corrected spectra. Nevertheless, the exact reflectance values are not critical if we use such methods in image processing that compare only shapes of the known spectral library spectra with the image reflectance spectra. Spectral Angel Mapper [63] classification normalizes both the spectral library and image reflectance before comparing; then in the n-dimensional space and the absolute value of reflectance is not important. However, in addition to the change in reflectance values, the glint correction procedure can also slightly change the spectral shape [64], resulting in mismatches between image spectra and spectral library spectra.

It must be noted that there are different glint removal methods based on different principles: some utilize NIR bands to estimate the amount of glint in every pixels [39], some use the depth of oxygen absorption feature [64] and there are also glint removal methods using the slope of reflectance spectra in the UV part of spectrum [48]. The latest two methods have been developed by us. Unfortunately, we used a CASI configuration that had just one band in the 350-380 $\mathrm{nm}$ range. This means we could not use the method described in [48]. Kay et al. [65] compared the method developed by us [64] with the methods proposed by Hedley et al. [39]. The latter provided more reliable results and was therefore used in this study. No comparative glint removal exercise was undertaken in the present study.

It's also necessary to pay more attention to tuning the modelling of the spectral library for particular conditions. For example, we used HydroLight with the concentrations of optically active substances (chlorophyll-a, CDOM, suspended matter). This means we adopted several empirical relationships that are built in the HydroLight. Most of those algorithms have been determined for clear oceanic waters and are not necessarily valid in turbid coastal waters. This explains also why the modelled spectra did 
not match exactly to the in situ measured reflectance spectra. The HydroLight model allows the use of inherent optical properties of the water (i.e., absorption coefficient, scattering coefficient and scattering phase function) instead of concentrations of optically active substances. We have the opportunity to use a set of optical instrumentation that allows us to measure the absorption, attenuation and scattering coefficient of water (ac-spectra by WETLabs), backscattering coefficient (eco-bb3 by WETLabs) and volume scattering function at three angles and three wavelengths (eco-vsf3 by WETLabs). Therefore, the next step should be parameterizing the HydroLight with real inherent optical properties (IOP) measurements in order to see if we can get more accurate water reflectance spectra for our spectral library.

Another potential source of error may be optical variability in the study area. Inner bay (from where we do not have IOP data) has brown CDOM-rich water. The central bay has a relatively high CDOM concentration, but also the amount of sediments may be high in windy conditions. Open water parts of the CASI image contained phytoplankton (probably cyanobacterial) bloom. Such extreme optical variability probably needs a spectral library containing spectra of more than two water types.

The result of the study may be slightly biased, due to the choice of method used in comparing spectra. Several authors $[66,67]$ have used the least squares method for that. This allows us to utilize both the shape and magnitude of reflectance spectra. Obtaining correct reflectance spectra is a very difficult task in the case of coastal waters, as more than $90 \%$ of the signal measured by satellite may be due to atmospheric contribution. Achieving correct spectral shape with different atmospheric correction methods is easier than achieving the correct absolute value of reflectance. Therefore, many authors [14,49,68-70] have used methods, like Spectral Angle Mapper, which are insensitive to illumination effects. We preferred to use SAM in our study.

\section{Conclusions}

Two image processing approaches were tested in the study-image-based approach and spectral library approach. The image-based approach requires lots of in situ data and an experienced interpreter in order to produce acceptable accurate shallow water habitat maps. The spectral library approach should be easier to use by an inexperienced image interpreter; it is easily transferable between sensors and sites and, unlike the image-based method, produces bottom type and water depth estimations simultaneously. However, the spectral library approach needs good atmospheric correction of imagery and a model well parameterized for the waters under investigation. The image-based method performed slightly better in our study than the spectral library method. It can be explained by the radiative transfer model used by us. It included some standard relationships embedded in the HydroLight model, which are not necessarily valid in such turbid waters, like the Haapsalu Bay. We need to redesign the model taking into account our IOP measurement results from Estonian coastal waters. The study also showed that some field reflectance measurements from the study area are very beneficial in improving atmospheric correction results.

We also compared the suitability of two types of imagery for shallow water habitat mapping. Our results show that there was no significant difference between using airborne hyperspectral and satellite multispectral data. This can be explained by relatively low variability in reflectance spectra. First of

all, the number of habitat classes was low, and the water was very turbid, smoothing potential narrow features in the reflectance spectra of different bottom types. Therefore, the higher number of spectral 
bands of the airborne sensor did not have a significant spectral advantage over the multispectral satellite data.

\section{Acknowledgements}

This work was funded by the Central Baltic Interreg IVa Programme, HISPARES, the Estonian Targeted Financing Grants SF0180009s11 and the Estonian Science Foundation Grant 8576.

We wish to thank DigitalGlobe for providing WorldView-2 images. Special thanks to Gregory Miecznik from Digitalglobe.

\section{References}

1. HELCOM. Ecosystem Health of the Baltic Sea 2003-2007. HELCOM Initial Holistic Assessment. Baltic Sea Environment Proceedings No. 122; Helsinki Commission: Helsinki, Finland, 2010. Available online: http://www.helcom.fi/stc/files/Publications/Proceedings/bsep122.pdf (accessed on 15 December 2012).

2. Kotta, J.; Paalme, T.; Martin, G.; Mäkinen, A. Major changes in macroalgae community composition affect the food and habitat preference of Idotea baltica. Int. Rev. Hydrobiol. 2000, 85, 693-701.

3. Torn, K.; Krause-Jensen, D.; Martin, G. Present and past depth distribution of bladderwrack (Fucus vesiculosus) in the Baltic Sea. Aquat. Bot. 2006, 84, 53-62.

4. Thomsen, M.; Wernberg, T.; Engelen, A.; Tuya, F.; Vanderklift, M.; Holmer, M.; McGlathery, K.; Arenas, F.; Kotta, J.; Silliman, B. A meta-analysis of seaweeds impact on seagrasses: generalities and knowledge gaps. PLoS ONE 2012, 7, e28595.

5. Kotta, J.; Aps, R.; Orav-Kotta, H. Bayesian Inference for Predicting Ecological Water Quality under Different Climate Change Scenarios. In Management of Natural Resources, Sustainable Development and Hazards II; WIT Press: Sussex, UK, 2009; pp. 127, 173-184.

6. Phinn, S.R.; Dekker, A.G.; Brando, V.E.; Roelfsema, C.M. Mapping water quality and substrate cover in optically complex coastal and reef waters: An integrated approach. Mar. Pollut. Bull. 2005, 51, 459-469.

7. Malthus, T.J.; Karpouzli, E. Integrating field and high spatial resolution satellitebased methods for monitoring shallow submersed aquatic habitats in the Sound of Eriskay, Scotland, UK. Int. J. Remote Sens. 2003, 24, 2585-2593.

8. Darecki, M.; Stramski, D. An evaluation of MODIS and SeaWiFS bio-optical algorithms in the Baltic Sea. Remote Sens. Environ. 2004, 89, 326-350.

9. Kutser, T.; Paavel, B.; Metsamaa, L; Vahtmäe, E. Mapping coloured dissolved organic matter concentration in coastal waters. Int. J. Remote Sens. 2009, 30, 5843-5849.

10. Kutser, T.; Metsamaa, L.; Vahtmäe, E.; Aps, R. Operative monitoring of the extent of dredging in coastal ecosystems using MODIS satellite imagery. J. Coastal Res. 2007, SI50, 180-184.

11. Kutser, T.; Metsamaa, L.; Strömbeck, N.; Vahtmäe, E. Monitoring cyanobacterial blooms by satellite remote sensing. Estuar. Coast. Shelf Sci. 2006, 67, 303-312.

12. Vahtmäe, E.; Kutser, T.; Kotta, J.; Pärnoja, M. Detecting patterns and changes in a complex benthic environment of the Baltic Sea. J. Appl. Remote Sens. 2011, 5, 053559. 
13. Dekker, A.G.; Brando, V.E.; Anstee, J.M. Retrospective seagrass hange detection in a shallow coastal tidal Australian lake. Remote Sens. Environ. 2005, 97, 415-433.

14. Kutser, T.; Miller, I.; Jupp, D.L.B. Mapping coralreef benthic substrates using hyperspectral space-borne images and spectral libraries. Estuar. Coast. Shelf Sci. 2006, 70, 449-460.

15. Phinn, S.; Roelfsema, C.; Dekker, A.; Brando, V.; Anstee, J. Mapping seagrass species, cover and biomass in shallow waters: An assessment of satellite multi-spectral and airborne hyper-spectral imaging systems in Moreton Bay (Australia). Remote Sens. Environ. 2008, 112, 3413-3425.

16. Bertels, L.; Vanderstraete, T.; Van Coillie, S.; Knaeps, E.; Sterckx, S.; Goossens, R; Deronde, B. Mapping of coral reefs using hyperspectral CASI data; A case study: Fordata, Tanimbar, Indonesia. Int. J. Remote Sens. 2008, 29, 2359-2391.

17. Fearns, P.R.C.; Klonowski, W.; Babcock, R.C.; England, P.; Phillips, J. Shallow water substrate mapping using hyperspectral remote sensing. Cont. Shelf Res. 2011, 31, 1249-1259.

18. Lyons, M.; Phinn, S.; Roelfsema, C. Integrating QuickBird multi-spectral satellite and field data: mapping bathymetry, seagrass cover, seagrass species and change in Moreton Bay, Australia in 2004 and 2007. Remote Sens. 2011, 3, 42-64.

19. Mumby, P.J.; Edwards, A.J. Mapping marine environments with IKONOS imagery: Enhanced spatial resolution can deliver greater thematic accuracy. Remote Sens. Environ. 2002, 82, 248-257.

20. Andrefouet, S.; Kramer, P.; Torres-Pulliza, D.; Joyce, K.E.; Hochberg, E.J.; Garza-Perez, R.; Mumby, P.J.; Riegl, B.; Yamano, H.; White, W.H.; et al. Multi-site evaluation of IKONOS data for classification of tropical coral reef environments. Remote Sens. Environ. 2003, 88, 128-143.

21. Call, K.A.; Hardy, J.T.; Wallin, D.O. Coral reef habitat discrimination using multivariate spectral analysis and satellite remote sensing. Int. J. Remote Sens. 2003, 24, 2627-2639.

22. Wolter, P.T.; Johnston, C.A.; Niemi, G.J. Mapping submerged aquatic vegetation in the US Great Lakes using Quickbird satellite data. Int. J. Remote Sens. 2005, 26, 5255-5274.

23. Pasqualini, V.; Pergent-Martini, C.; Pergent, G.; Agreil, M.; Skoufas, G.; Sourbes, L.; Tsirika, A. Use of SPOT 5 for mapping seagrasses: An application to Posidonia oceanica. Remote Sens. Environ. 2005, 94, 39-45.

24. Fornes, A.; Basterretxea, G.; Orfila, A.; Jordi, A.; Alvarez, A.; Tintore, J. Mapping Posidonia oceanica from IKONOS. ISPRS J. Photogranmm. 2006, 60, 315-322.

25. Theriault, C.; Scheibling, R.; Hatcher, B.; Jones, W. Mapping the distribution of an invasive marine alga (Codium fragile spp. tomentosoides) in optically shallow coastal waters using the compact airborne spectrographic imager (CASI). Can. J. Remote Sens. 2006, 32, 315-329.

26. Gagnon, P.; Scheibling, R.E.; Jones, W.; Tully, D. The role of digital bathymetry in mapping shallow marine vegetation from hyperspectral image data. Int. J. Remote Sens. 2008, 29, 879-904.

27. Schowengerdt, R.A. Remote Sensing Models and Methods for Image Processing; Academic Press: Burlington, MA, USA, 1997.

28. Chen, D.M.; Stow, D. The effect of training strategies on supervised classification at different spatial resolutions. Photogramm. Eng. Remote Sensing 2002, 68, 1155-1161.

29. Campbell, J.B. Introduction to Remote Sensing, 4th ed.; The Guilford Press: New York, NY, USA, 2007. 
30. Louchard, E.M.; Reid, R.P.; Stephens, F.C.; Davis, C.O.; Leathers, R.A.; Downes, T.V. Optical remote sensing of benthic habitats and bathymetry in coastal environments at Lee Stocking Island, Bahamas: A comparative spectral classification approach. Limnol. Oceanogr. 2003, 48, 511-521.

31. Lesser, M.P.; Mobley, C.D. Bathymetry, water optical properties, and benthic classification of coral reefs using hyperspectral remote sensing imagery. Coral Reefs 2007, 26, 819-829.

32. Jaanus, A. Phytoplankton in Estonian Coastal Waters: Variability, Trends and Response to Environmental Pressures. Ph.D. Dissertation, Biologicae Universitatis Tartuensis, Tartu University, Tartu, Estonia, 2011.

33. Kotta, J.; Jaanus, A.; Kotta, I. Haapsalu and Matsalu Bays. In Ecology of Baltic Coastal Waters; Schiewer, U., Ed.; Springer-Verlag: Berlin/Heidelberg, Germany, 2008; Chapter 11, pp. 245-258.

34. Kovtun, A.; Torn, K.; Kotta, J. Long-term changes in a northern Baltic macrophyte community. Estonian J. Ecol. 2009, 58, 270-285.

35. Möller, T.; Kotta, J; Martin, G. Effect of observation method on the perception of community structure and water quality in a brackish water ecosystem. Marine Ecol. 2009, 30, 105-112.

36. Morel, A.; Gentili, B. Diffuse reflectance of oceanic waters. II Bidirectional aspects. Appl. Opt. 1993, 32, 6864-6879.

37. Mobley, C.D.; Sundman, L.K. HydroLight 5, Ecolight 5 Users Guide; Sequoia Scientific Inc.: Bellevue, WA, USA, 2008.

38. Holden, H.; LeDrew, E. Measuring and modeling water column effects on hyperspectral reflectance in a coral reef environment. Remote Sens. Environ. 2002, 81, 300-308.

39. Hedley, J.D.; Harborne, A.R.; Mumby, P.J. Simple and robust removal of sun glint for mapping shallow-water benthos. Int. J. Remote Sens. 2005, 26, 2107-2112.

40. Adler-Golden, S.M.; Matthew, M.W.; Bernstein, L.S.; Levine, R.Y.; Berk, A.; Richtsmeier, S.C.; Acharya, P.K.; Anderson, G.P.; Felde, G.; Gardner, J.; et al. Atmospheric correction for shortwave spectral imagery based on MODTRAN4. Proc. SPIE 1999, 3753, 61-69.

41. DigitalGlobe Inc. The Benefits of the 8 Spectral Bands of WorldView-2; White Paper; 2010. Available online: www.digitalglobe.com (accessed on 25 March 2013).

42. Kruse, F.A.; Dwyer, J.L. The Effect of AVIRIS Atmospheric Calibration Methodology on Identification and Quantification Mapping of Surface Mineralogy, Drums Mountain, Utah. In Proceedings of the 4th JPL Airborne Geoscience Workshop, Washington, DC, USA, 25-29 October 1993; pp. 101-104.

43. Vahtmäe, E.; Kutser, T.; Kotta, J.; Pärnoja, M.; Möller, T.; Lennuk, L. Mapping Baltic Sea shallow water environments with airborne remote sensing. Okeanology 2012, 52, 870-876.

44. Lillesand, T.M.; Kiefer, R.W.; Chipman, J.W. Remote Sensing and Image Interpretation; John Wiley \& Sons: New York, NY, USA, 2007.

45. Kutser, T.; Hiire, M.; Metsamaa, L.; Vahtmäe, E.; Paavel, B.; Aps, R. Field measurements of spectral backscattering coefficient of the Baltic Sea and boreal lakes. Boreal Environ. Res. 2009, 14, 305-312.

46. Metsamaa, L.; Kutser, T.; Strömbeck, N. Recognising cyanobacterial blooms based on their optical signature: a modelling study. Boreal Environ. Res. 2006, 11, 493-506.

47. Nobel, P.S. Physicochemical and Environemntal Plant Physiology, 4th ed.; Elsevier Inc.: Oxford, UK, 2009. 
48. Kutser, T.; Vahtmäe, E.; Paavel, P.; Kauer, T. Removing glint effets from field radiometry data measured in optically complex coastal and inland waters. Remote Sens. Environ. 2013, 133, $85-89$.

49. Belluco, E.; Camuffo, M.; Ferrari, S.; Modenese, L.; Silvestri, S.; Marani, A.; Marani, M. Mapping salt-marsh vegetation by multispectral and hyperspectral remote sensing. Remote Sens. Environ. 2006, 105, 54-67.

50. Hochberg, E.J.; Atkinson, M.J. Capabilities of remote sensors to classify coral, algae, and sand as pure and mixed spectra. Remote Sens. Environ. 2003, 85, 174-189.

51. Andrefouet, S.; Payri, C.; Hochberg, E.J.; Hu, C.; Atkinson, M.J.; Muller-Karger, F.E. Use of in situ and airborne reflectance for scaling-up spectral discrimination of coral reef macroalgae from species to communities. Marine Ecol. Progr. Series 2004, 283, 161-177.

52. Kutser, T.; Vahtmäe, E.; Metsamaa, L. Spectral library of macrolagae and benthic substrates in Estonian coastal waters. Proc. Estonian Acad. Sci. Biol. Ecol. 2006, 55, 329-340.

53. Foody, G. On the compensation for chance agreement in image classification accuracy assessment. Photogramm. Eng. Remote Sensing 1992, 58, 1459-1460.

54. Rosenfield, G.; Fitzpatrick-Lins, K. A Coefficient of agreement as a measure of thematic classification accuracy. Photogramm. Eng. Remote Sensing 1986, 52, 223-227.

55. Giardino, C.; Bartoli, M.; Candiani, G.; Bresciani, M. and Pellegrini, L. Recent changes in macrophyte colonisation patterns: An imaging spectrometry-based evaluation of southern Lake Garda (northern Italy). J. Appl. Remote Sens. 2007, 1, 011509.

56. Williams, D.J.; Rybicki, N.B.; Lombana, A.V.; O’Brien, T.M.; Gomez, R.B. Preliminary investigation of submerged aquatic vegetation mapping using hyperspectral remote sensing. Environ. Monit. Assess. 2003, 81, 383-392.

57. Mishra, D.; Narumalani, S.; Rundquist, D.; Lawson, M.; Perk, R. Enhancing the detection and classification of coral reef and associated benthic habitats: A hyperspectral remote sensing approach. J. Geophys. Res. 2007, 112, C08014.

58. Lyons, M.; Phinn, S.; Roelfsema, C. Integrating QuickBird multi-spectral satellite and field data: Mapping bathymetry, seagrass cover, seagrass species and change in Moreton Bay, Australia in 2004 and 2007. Remote Sens. 2011, 3, 42-64.

59. Kutser, T.; Pierson, C.D.; Kallio, K.Y.; Reinart, A.; Sobek, S. Mapping lake CDOM by satelliite remonte sensing. Remote Sens. Environ. 2006, 94, 535-540.

60. Kutser, T. Quantitative detection of chlorophyll in cyanobacterial blooms by satelliite remonte sensing. Limnol. Oceanogr. 2004, 49, 2179-2189.

61. O’Neill, J. D.; Costa, M.; Sharma, T. Remote sensing of shallow coastal benthic substrates: In situ spectra and mapping of eelgrass (Zostera marina) in the Gulf Islands National Park Reserve of Canada. Remote Sens. 2011, 3, 975-1005.

62. Vahtmae, E.; Kutser, T.; Martin, G.; Kotta, J. Feasibility of hyperspectral remote sensing for mapping benthic macroalgal cover in turbid coastal waters-A Baltic Sea case study. Remote Sens. Environ. 2006, 101, 342-351.

63. Kruse, F.; Lefkoff, A.; Boardman, A.B.; Heidebrecht, K.B.; Shapiro, A.T.; Barloon, P.J.; Goetz, A.F.H. The Spectral Image Processing System (SIPS) dinteractive visualization and analysis of imaging spectrometer data. Remote Sens. Environ. 1993, 44, 145-163. 
64. Kutser, T.; Vahtmäe, E.; Praks, J. A sun glint correction method for hyperspectral imagery containing areas with non-negligible water leaving NIR signal. Remote Sens. Environ. 2009, 113, 2267-2274.

65. Kay, S.; Hedley, J.D.; Lavender, S. Sun glint correction of high and low spatial resolution images of aquatic scenes: A review of methods for visible and near-infrared wavelengths. Remote Sens. 2009, 1, 697-730.

66. Mobley, C.D.; Sundman, L.K, Davis, C.O.; Bowles, J.H.; Downes, T.V.; Leathers, R.A.; Montes, M.J.; Bissett, W.P.; Kohler, D.D.; Reid, R.P.; et al. Interpretation of hyperspectral remote-sensing imagery by spectrum matching and look-up tables. Appl Opt. 2005, 44, 3576-3592.

67. Dekker, A.G.; Phinn, S.R.; Anstee, J.; Bissett, P.; Brando, V.E.; Casey, B.; Fearns, P.; Hedley, J.; Klonowski, W.; Lee, Z.P.; et al. Intercomparison of shallow water bathymetry, hydro-optics, and benthos mapping techniques in Australian and Caribbean coastal environments. Limnol. Oceanogr.: Methods 2011, 9, 396-425

68. Casal, G.; Kutser, T.; Dominguez-Gomez, J.A.; Sanchez-Carnero, N.; Freire, J. Mapping benthic macroalgal communities in the coastal zone using CHRIS-PROBA mode 2 images. Estuarine Coastal Shelf Sci. 2011, 94, 281-290.

69. Casal, G.; Sanchez-Carnero, N.; Dominguez-Gomez, J. A.; Kutser, T.; Freire. J. Assessment of AHS (Airborne Hyperspectral Scanner) sensor to map macroalgal communities on the Ria de vigo and Ria de Aldan coast (NW Spain). Mar. Biol. 2012, 159, 1997-2013.

70. Hestir, E.L.; Khanna, S.; Andrew, M.E.; Santos, M.J.; Viers, J.H.; Greenberg, J.A.; Rajapakse, S.S.; Ustin, S.L. Identification of invasive vegetation using hyperspectral remote sensing in the California Delta ecosystem. Remote Sens. Environ. 2008, 112, 4034-4047.

(C) 2013 by the authors; licensee MDPI, Basel, Switzerland. This article is an open access article distributed under the terms and conditions of the Creative Commons Attribution license (http://creativecommons.org/licenses/by/3.0/). 